\title{
Antioxidant Therapies for Hypolipidemia and Hyperglycemia
}

\author{
Dawei Gao
}

Additional information is available at the end of the chapter

http://dx.doi.org/10.5772/47432

\section{Introduction}

High level fat, obesity and metabolic syndrome may increase oxidative stress, and/or influence the levels of cellular homeostasis (Gao et al., 2011; Furukawa et al., 2004). Thus, oxidative damage and its consequences may result in many chronic health problems. For example, atherosclerosis, cancer, hyperlipidemia, hyperglycemia, and arthritis have been correlated with oxidative damage (Brown and Bicknell., 2001; Alexander, 1995). Diabetes mellitus (DM) can be defined as a group of syndromes due to defects in pancreatic secretion of insulin or insulin action, which characterized by hyperglycemia, altered metabolism of lipids, carbohydrates and proteins along with an increased risk of complications from vascular disease (Taskinen et al., 2002). Hyperglycemia impairs the prooxidant/antioxidant balance, increasing free radical and reducing antioxidant levels (Aragno et al., 2004). Free radicals react with lipids and cause peroxidative changes that result in enhanced lipid peroxidation (Girotti, 1985). The level of lipid peroxidation in cells is controlled by various cellular defense mechanisms consisting of enzymatic and nonenzymatic scavenging systems. The efficiency of the antioxidant defense mechanism is altered in diabetes (Wohaieb and Godin, 1987). Increased free radical production exerts cytotoxic effects on the membrane phospholipid, resulting in formation of toxic products such as MDA. The antioxidant scavenging enzymes superoxide dismutase (SOD), catalase (CAT) and glutathione peroxidase (GPX) offer protection to cells and tissues against oxidative injury (Bonnefont-Rousselot et al., 2000).

There are various reports indicating the beneficial effects of antioxidant supplementation in preventing dyslipidemia. Diet modification may be one way to reduce serum lipid level. Numerous studies have reported that lactic acid bacteria fermented food display hypolipidemic effects by inhibiting cholesterol biosynthesis and decreasing low-density lipoproteins (Haberer et al., 2003; Kawase et al., 2000). Momordica charantia fermented milk 
is effective in preventing and retarding hyperlipidemia and atherosclerosis in hamsters (Tsai et al., 2009), and some kinds of LAB could adjust blood lipid and lower cholesterol, which can prevent and treat some diseases by activating antioxidant enzymes (Jain et al., 2009). Some herbal drugs are a good source of natural antioxidants, and increased utilization of medicinal plants became a World Health Organization policy on 1970. Rhodiola sachalinensis A. Bor (Chinese Name: Hong jing tian) is a traditional Tibetan pharmacology, which distributed in Eastern Europe and Western Asia (altitude 3500-5000 meters). R. sachalinensis is a precious perennial herbaceous plant, and widely used as a traditional Tibetan medicine with the reputations for excitement nervous system, relieving fatigue, preventing high altitude sickness, decreasing depression, enhancing work performance, and resisting sideeffects of anoxia and microwave radiation (Stancheva and Mosharrof, 1987; Ming et al., 1988; Mook-Jung et al., 2007; Li et al., 2007). As a drug of "source of adaptation to environment", R. sachalinensis has been used in such special posts as diver, astronaut, pilot and mountaineer to enhance the body's ability surviving in adverse environments (MookJung, et al., 2002). Our study was performed to investigate the therapeutic effects of $R$. sachalinensis (RS) on diabetes and antioxidative ability in streptozotocin-induced diabetic rats. We found that RS could significantly stimulate insulin secretion, and possess antioxidative and antidiabetic potentials.

Ligustrum lucidum Ait (LLA) is a traditionally Chinese medicinal plant, known with a local name as "Nv zhenzi". It has been used to treat cancer whose tumor inhibitory rate was $46.15 \%$ (Xiang and $\mathrm{Gu}, 2002$ ). In addition, LLA was proven to have the abilities of antimutagenic (Wang et al., 1991), antidiabetic (Hao et al., 1992) and hepatoprotective properties (Yin and Yu, 1993). The hypoglycemic effect of oleanolic acid (OA) isolated from LLA was identified in streptozotocin-induced diabetic rats, at the same time, the ability of LLA stimulating secretion of insulin was disclosed in our study (Gao et al., 2007). In order to reveal the efficacy of LLA in alloxan-induced diabetic rats, the effects of OA from LLA were estimated on hypoglycemia, lipids modulating and antioxidant efficacy in alloxan-induced diabetic rats. Meanwhile, we investigate the effect of $\mathrm{OA}$ on serum level of hepatic enzymes and tissue level of lipid peroxidation and antioxidant enzymes in alloxan-induced diabetic rats.

Nuclear factor erythroid 2-related factor 2 (Nrf2) controls the antioxidant response element (ARE)-dependent gene regulation in response to oxidative stress. Nrf2 regulates the transcriptional activation of more than 200 antioxidant and protective genes that constitute the so-called phase II response. Examples of phase II enzymes (p2Es) include the ratelimiting enzyme in the GSH synthesis pathway, glutathione peroxidase (GPx), as well as superoxide dismutase (SOD), heme oxygenase 1, $\gamma$-gluta-mylcysteine ligase, glutathione Stransferase, and reduced nicotinamide adenine dinucleotide phosphate-quinone oxidoreductase (Matafome et al., 2011; Gao et al.,2009 ). Some strains and species of lactic acid bacteria (LAB) have the antioxidative activity (Gao et al., 2011; Sotiroudis et al., 2010). A number of Lactobacillus species, Bifidobacterium sp, Saccharomyces boulardii, and some other microbes have been proposed as and are used as probiotic strains, i.e. live microorganisms as food supplement in order to benefit health. Fermented cabbages, one of the most important foods in the traditional Chinese diet, hold a wide variety of LAB which may have 
interesting features for application in health. Fermented cabbages have made up a significant part of food intake in Asia countries for several centuries, including China, Japan, Korea, and so on. In our study, 28 LAB strains were isolated from pickled cabbage, and two strains with high acid tolerance and bile salt resistance were screened, which were Lactobacillus plantarum and Lactobacillus brevis. The two strains were given to the normal, hyperlipidemic mice by ig. $28 \mathrm{~d}$ continually. Activities of antioxidant enzymes in liver and kidney tissues were observed, parameter of blood lipid was examined, and their effects of hypoglycemia and hypolipidemia were analyzed. The experiment was designed to determine whether the antioxidative effects of lactic acid bacteria from fermented cabbage are mediated, at least in part, by the activation of Nrf2. We analysed the scavenging effects of superoxide anion radicals and hydrogen peroxide of the strains isolated from fermental cabbages in vitro, and evaluate liver antioxidative activities related to the elimination of reactive oxygen species in L.plantarum-treated high-fat diet mice. Meanwhile, the Nrf2mediated antioxidant defense pathway and immune status of the lactic acid bacteria-treated mice were investigated.

The present study was performed to investigate the antioxidant therapeutic effects and mechanism of $R$. sachalinensis, oleanolic acid and lactic acid bacteria on hypolipidemia and hyperglycemia, especially with respect to lipids modulating, and antioxidative ability in diabetic rats. We found that they could significantly stimulate lipid metabolizing, and possess antioxidative, hypolipidemic and hypoglycemic potentials.

\section{Antidiabetic and antioxidative potentials of Rhodiola sachalinensis polysaccharide}

Rhodiola sachalinensis has been used as one of Tibet traditional herbs, which possesses antifatigue, anti-lacking oxygen, anti-microwave radiation and anti-caducity potentials. In the study, we examined the antidiabetic effect and probable mechanisms of Rhodiola sachalinensis root extract (RS), its main compound was polysaccharide. RS in the streptozotocin-induced diabetic rats showed significant hypoglycemic activity. The levels of serum total cholesterol (TC) and triglcerides (TG) of RS-treated diabetic rats were lower than control diabetic rats. A significant enhancement in the serum insulin levels of diabetic rats following RS treatment was also observed. Furthermore, RS treatment decreased malondialdehyde (MDA) level, while increased SOD, CAT and GSH-px activities of the liver and kidney of diabetic rats. At the same time, RS has not expressed significant toxicity in LD 50 test and single cell gel electrophoresis assay. These results indicate that RS has the hypoglycemic and hypolipidemic activities, which is an effective scavenger of free radicals to inhibit the lipid peroxidation. The abilities of antioxidation and protecting pancreatic $\beta$ cells might be the main mechanisms of RS on antidiabetic effect.

\subsection{Preparation and characterization of $R$. sachalinensis}

Dried R. sachalinensis root was ground to fine powder, and refluxed three times (each time for $1 \mathrm{~h})$ to remove lipids with chloroform: methanol solvent at $80^{\circ} \mathrm{C}(2: 1)(\mathrm{v} / \mathrm{v})$. After filtering 
the residue was air-dried and then refluxed again with $80 \%$ ethanol to remove monosaccharide and oligosaccharide. The residue was extracted three times in $\mathrm{dH}_{2} \mathrm{O}\left(60^{\circ} \mathrm{C}\right)$ and then combined filtrate to concentrate through decompressing using a rotary evaporator, after then the precipitate was added $80 \%$ ethanol and deposited for $12 \mathrm{~h}$ in $4^{\circ} \mathrm{C}$. The precipitation was washed by $95 \%$ and $100 \%$ ethanol, respectively. After filtering and centrifuging, the precipitate was collected and vacuum-dried, obtaining light brown extracts, named RS. The extract was examined by thin layer chromatography (TLC) analysis to identify the main compounds. RS solution was dotted on the TLC plates, and nbutanol:acetic acid: $\mathrm{H}_{2} \mathrm{O}$ (20:9:1) was used as the solvent system, then the different indicators were sprayed on the plates, respectively(Sezik et al., 2005). The plates were heated at $105^{\circ} \mathrm{C}$ for $10 \mathrm{~min}$. Nine kinds of indicator system were used to identify the compounds of RS, and different color spots were visualized (Gao et al., 2009). The results were shown on Table 1, which indicated that the main compound in RS was polysaccharide, meanwhile including a little of flavone, saponin and organic acid, but no alkaloide, anthraquinone, hydroxybenzene, terpene, steroid and lignin were detected. These results have indicated that polysaccharide is the main ingredient of the extract of $R$. sachalinensis root extracts prepared using the above mentioned procedure.

\begin{tabular}{lccc}
\hline \multicolumn{1}{c}{ Indicator } & $\begin{array}{c}\text { examined } \\
\text { Components }\end{array}$ & $\begin{array}{c}\text { Ratio of } \\
\text { Flow(Rf) }\end{array}$ & Color \\
\hline phenol / sulfuric acid & polysaccharide & $0.193-0.553$ & brown \\
$10 \% \mathrm{NaOH}$ & flavone & $0.248-0.463$ & yellow \\
bromophenol blue / ethanol & organic acid & $0.278-0.564$ & dark yellow \\
phosphomolybdic acid / ethanol & saponin & $0.217-0.493$ & dark blue \\
ferric trichloride / water & hydroxybenzene & - & - \\
acetic anhydride / sulfuric acid & terpene and steroid & - & - \\
$10 \% \mathrm{KOH}$ & anthraquinone & - & - \\
iodine / potassic iodide & alkaloide & - & - \\
sulfuric acid / ethanol & lignin & - & - \\
\hline
\end{tabular}

Note: "-"means without any spot on the plates.

Table 1. Compounds of RS Extracts by TLC Analysis

\subsection{Preparation of STZ-induced diabetic rats}

Male wistar rats weighing 180-200 g were obtained from the animal department of Beijing institute of traditional medical and pharmaceutical sciences. The animals were housed under suitable lighting and temperature. Food and drinking water were provided. Following one week of acclimation, eight rats were randomly assigned as normal control group, and the rest rats, treated with STZ, became the diabetic model rats according to the standard method (Gao et al., 2007). The rats with blood glucose levels above $15.0 \mathrm{mM}$ were 
defined as diabetic model rats. Thirty-two rats (eight normal rats, twenty-four diabetic rats) were chosen and randomly divided into four groups: normal control group (NC), DM control group (DC), DM + RS low dose group (DM+RS LD), and DM+RS high dose group (DM+RS HD).

\subsection{Examination of effect of RS in the oral glucose tolerance test}

On the first day, after overnight fasting with free access to water, the rats were administered RS solution by oral gavage at the following doses: 200 or $400 \mathrm{mg} / \mathrm{kg} \cdot \mathrm{bw}$ for the DM+RS LD \& DM+RS HD groups, and with the same volume of $\mathrm{dH}_{2} \mathrm{O}$ alone for the $\mathrm{NC}$ and DC groups. Tail blood samples were drawn from each rat, then a glucose $(2.0 \mathrm{~g}$ $/ \mathrm{kg} \cdot \mathrm{bw})$ solution was orally administered by oral gavage after $30 \mathrm{~min}$ following RS administration. Blood samples were taken at 30,60, 90, and 120 min intervals following glucose administration, and blood glucose levels were measured at various time points. The supplement of RS improved the acute blood glucose levels in the rats (Figure 1). There was no significant difference at $0 \mathrm{~h}$ between the DC and RS-treated groups, but in the RS LD and HD groups, hypoglycemic effect of RS became significant $1 \mathrm{~h}$ following oral administration comparing with DC group $(p<0.01)$, then the decreased rates were $22.3 \%$ and $24.4 \%$ at $2 \mathrm{~h}$ after oral administration, respectively. However, the blood glucose levels in diabetic control rats declined after $90 \mathrm{~min}$, but it was still high during the experiment. Moreover, the blood glucose level of DM + RS HD was not significantly different with that of DM + RS LD $(p>0.05)$.

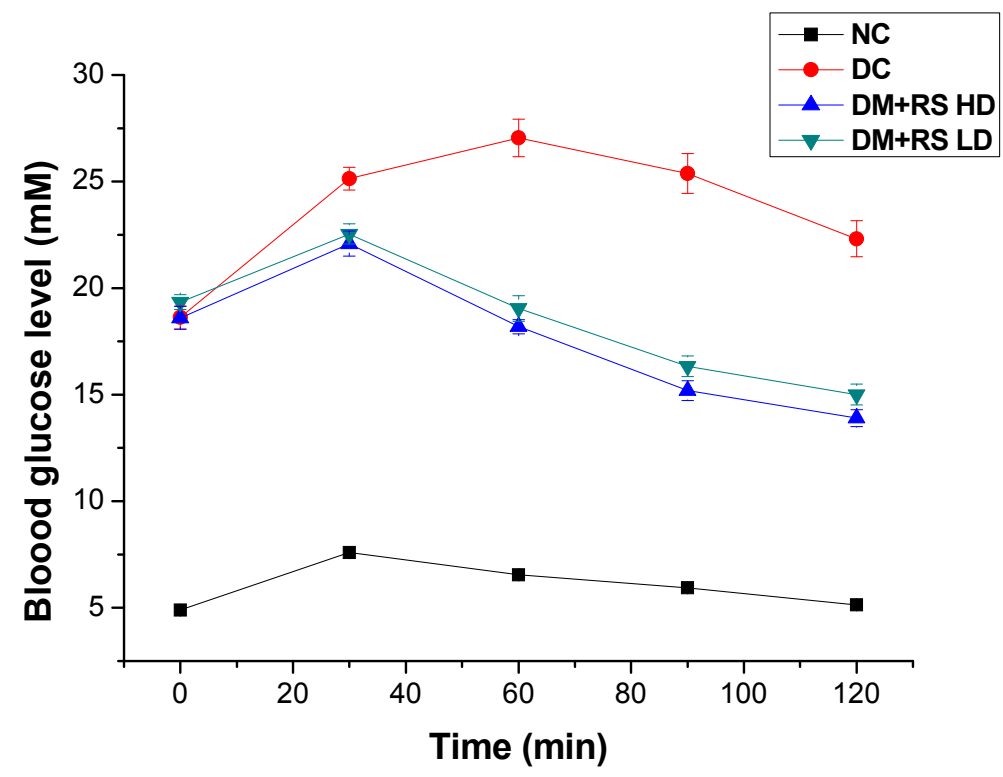

The values represent the means $\pm \mathrm{SE}$. of eight rats per group.

Figure 1. Acute effect of RS treatments in OGTT for STZ-induced diabetic and control rats. 


\subsection{Determination of subacute effect of RS treatment on blood glucose level}

In the DM+RS LD and HD groups, the rats were given RS solution ( $200 \& 400 \mathrm{mg} / \mathrm{kg} \cdot \mathrm{bw}$ ) daily by gavage for 40 days, respectively. The control rats (NC and DC groups) were given the same volume of $\mathrm{dH}_{2} \mathrm{O}$. On days $0,10,20,30$ and 40 , the blood samples were collected from rat's tail veins and measured, followed by an overnight fast. Changes of plasma glucose level as a result of RS treatment for 40 days are shown in Figure 2. Before treatment of diabetic rats, there was no significant difference for the blood glucose levels among diabetic rats $(p>0.05)$. They were consistently staying at similar levels within the experimental course in NC \& DC groups. However, in DM +RS treated groups significantly lower blood glucose levels were observed as compared to DC group at the same time points, from day 10 to day $40(p<0.01)$. The decreasing rates of the blood glucose were $45.51 \%$ (DM + RS LD group) and $55.11 \%$ (DM + RS HD group), respectively. The difference of dose-effect of RS was not significant according to the results of blood glucose levels of RS-treated groups $(p>0.05)$.

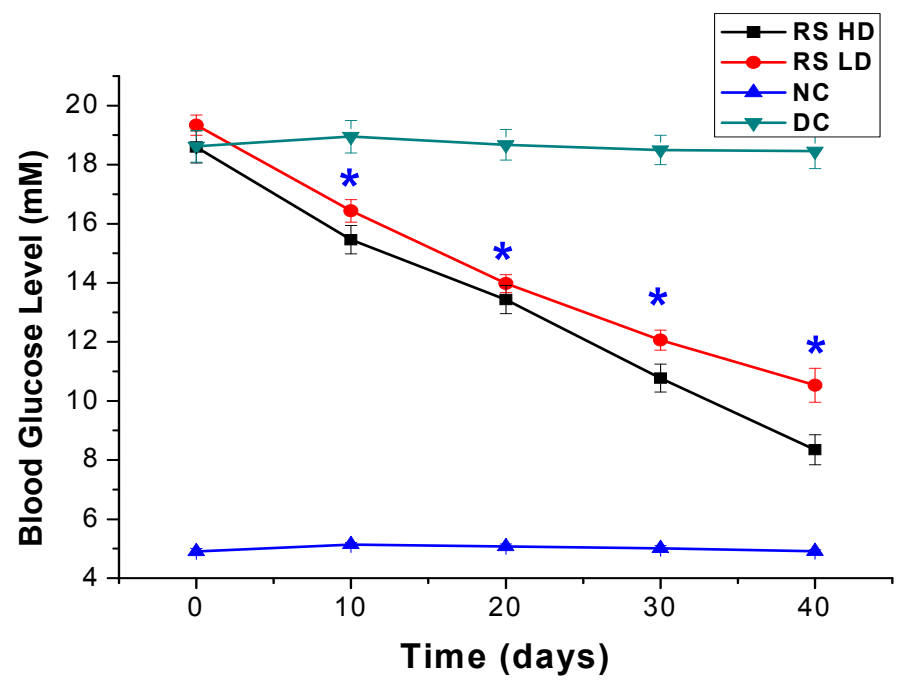

The values represent the means \pm SE. of eight rats per group; ${ }^{*} p<0.01$ vs. diabetes control group (DC) at the same time point.

Figure 2. Subacute effect of RS treatment on blood glucose level of STZ-induced diabetic rats.

The oral administration of RS for 40 days for the STZ-induced diabetic rats showed a significant reduction in blood glucose, which elucidate that $R$. sachalinensis has obvious hypoglycemic potential. In a healthy person, plasma glucose concentrations are maintained within a fairly narrow range in the fasting state, even if no food is ingested for many days. However, after glucose intake an acute increase in plasma glucose is seen, the concentration peaking generally within $1 \mathrm{~h}$. Plasma glucose then decreases and fasting levels are regained by $2 \mathrm{~h}$ post ingestion (Choi, et al., 2008). The acute hypoglycemia of diabetic rats was seen after RS-treated $1 \mathrm{~h}$ in the oral glucose tolerance test, but it was still high in diabetic control rats, which imply that RS could improve the hyperglycemia in an acute course. 


\subsection{Determination of effects of RS treatment on blood biochemical parameters}

At the end of the experiment, the blood samples of fasted tested rats were collected from the eyes under ether anaesthesia, to determine the levels of TG, TC and insulin, according to commercial advice by the Automatic Biochemical Analyzer. The levels of TG and TC in DC rats were significantly higher compared with those of NC group (Table 2, $p<0.01$ ). When diabetic rats were treated with RS for 40 days, the levels of TG and TC were significantly decreased as compared to DC rats $(p<0.01)$, but which didn't fall to the normal levels. Meanwhile, there was difference on TG and TC levels between high and low dose groups ( $p$ $<0.05$ ), which indicated RS displaying dose-dependent ameliorative blood lipid effect within the range of $200 \sim 400 \mathrm{mg} / \mathrm{kg} \cdot \mathrm{bw}$. The situation of insulin secretion of the diabetic rats has been ameliorated by RS treatment (Figure 3). The levels of insulin in DC rats were significantly lower as compared to those of NC group $(p<0.01)$. When diabetic rats were treated with RS $(200,400 \mathrm{mg} / \mathrm{kg} \cdot \mathrm{bw})$ for 40 days, the serum insulin levels were significantly enhanced compared to DC group $(p<0.01)$, the increased rates were $20.79 \%$ and $29.68 \%$, and there are significant difference between low and high dose groups $(p<0.05)$. The results indicated that RS could stimulate insulin secretion in vivo by the dose-dependent manner.

\begin{tabular}{ccc}
\hline Groups & TC $(\mathrm{mg} / \mathrm{dl})$ & TG $(\mathrm{mg} / \mathrm{dl})$ \\
\hline NC & $83.288 \pm 3.084^{*}$ & $72.513 \pm 3.169^{*}$ \\
DC & $135.375 \pm 4.203$ & $170.438 \pm 3.376$ \\
DM+RS LD & $106.913 \pm 4.491^{*}$ & $94.075 \pm 3.837^{*}$ \\
DM +RS HD & $96.125 \pm 4.591^{*} \#$ & $84.188 \pm 4.121^{*}$ \\
\hline
\end{tabular}

Values are means $\pm \mathrm{SD}$ for eight rats in each group, ${ }^{*} p<0.01 \mathrm{vs}$. diabetic control group (DC), $\# p<0.05 \mathrm{vs.} \mathrm{DM+LD}$

Table 2. Effect of RS on TC and TG in normal and diabetic rats

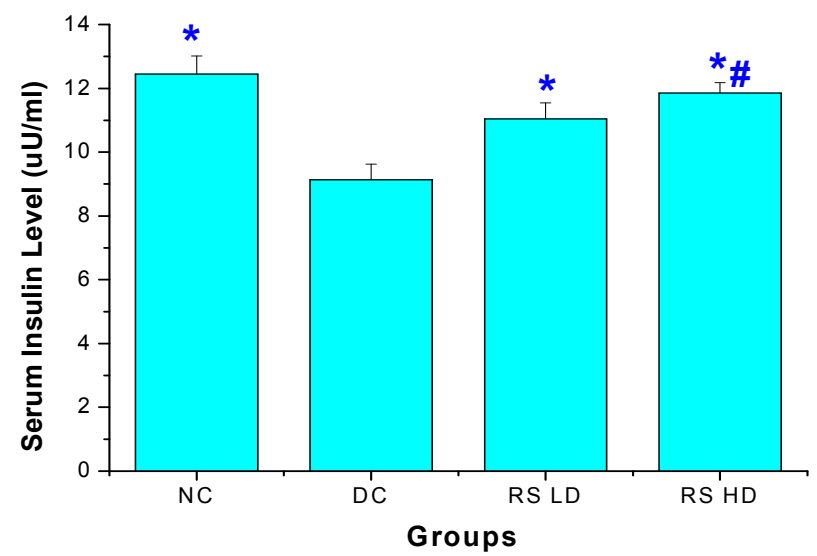

The values represent the means \pm SE. of eight rats per group. ${ }^{*} p<0.01$ vs. diabetic control group (DC). $\# p<0.01$ vs.RS LD group.

Figure 3. Effect of RS treatment on insulin level of STZ-induced diabetic rats. 
Diabetes is a metabolic disorder affecting carbohydrate, lipid and protein metabolisms, complicated with multiorgans regression in the later period. The levels of serum lipids are usually raised in diabetes mellitus (Sakatani et al., 2005). The increase of blood glucose is accompanied with the rise of TC and TG (Sharma et al., 2003). The significant rise of blood glucose, TC and TG levels has been observed in STZ-induced diabetic rats, whereas those were significantly decreased by RS treatment. Our results suggested that RS not only possess significant hypoglycemic ability but also have remarkable hypolipidemic effect. RS also enhanced serum insulin release in STZ-diabetic rats by 40 days treatment, which was obviously different with the diabetic control rats. We presume that RS appears the hypoglycemic effect in diabetic rats is partly attributed to its stimulation of insulin secretion.

\subsection{Determination of tissue antioxidative enzyme activities}

The animals were sacrificed under ether anaesthesia. Their liver and kidney tissues were immediately removed, washed using chilled saline solution, homogenized in 4 volumes of Tris- $\mathrm{HCl}$ buffer ( $\mathrm{pH} 7.4$ ). The homogenates were centrifuged at $4,000 \times g$ for $20 \mathrm{~min}$ at $4^{\circ} \mathrm{C}$. The protein concentrations of the homogenates were determined by the Bradford method using bovine serum albumin as the standard (Bradford et al., 1976). The levels of SOD, MDA, CAT and GSH-px were measured by commercial suggestion of the kits, and the results are shown in Table 3. There was a significant increase in SOD, CAT and GSH-px

\begin{tabular}{lcccc}
\hline $\begin{array}{l}\text { Antioxidative } \\
\text { level in liver and } \\
\text { kidney tissues }\end{array}$ & NC & DC & DM+RS LD & DM+RS HD \\
\hline $\begin{array}{l}\text { Liver MDA } \\
\text { (nmol/mg.pro) }\end{array}$ & $8.105 \pm 0.329^{* *}$ & $10.848 \pm 0.455$ & $9.773 \pm 0.375$ & $9.132 \pm 0.374^{*}$ \\
$\begin{array}{l}\text { Kidney MDA } \\
\text { (nmol/mg.pro) }\end{array}$ & $9.701 \pm 0.269^{* *}$ & $12.315 \pm 0.352$ & $11.239 \pm 0.441$ & $10.604 \pm 0.236^{*}$ \\
$\begin{array}{l}\text { Liver SOD } \\
\text { (U/mg.pro) }\end{array}$ & $46.05 \pm 1.129^{* *}$ & $39.913 \pm 1.045$ & $43.45 \pm 1.018$ & $44.375 \pm 0.958^{*}$ \\
$\begin{array}{l}\text { Kidney SOD } \\
\text { (U/mg.pro) }\end{array}$ & $50.725 \pm 1.184^{* *}$ & $44.188 \pm 0.834$ & $47.263 \pm 0.927$ & $48.638 \pm 0.814^{*}$ \\
$\begin{array}{l}\text { Liver GSH-px } \\
\text { (U/mg.pro) }\end{array}$ & $24.849 \pm 0.944^{* *}$ & $16.959 \pm 0.734$ & $20.973 \pm 0.925^{*}$ & $21.848 \pm 1.136^{*}$ \\
$\begin{array}{l}\text { Kidney GSH-px } \\
\text { (U/mg.pro) }\end{array}$ & $32.321 \pm 0.795^{* *}$ & $24.438 \pm 0.600$ & $27.779 \pm 0.691^{*}$ & $30.853 \pm 0.898^{* *}$ \\
$\begin{array}{l}\text { Liver CAT (U/ml) } \\
\text { Kidney CAT }\end{array}$ & $20.176 \pm 0.551^{* *}$ & $14.786 \pm 0.390$ & $17.398 \pm 0.416^{*}$ & $18.776 \pm 0.597^{* *}$ \\
(U/ml) & $25.544 \pm 0.433^{* *}$ & $20.410 \pm 0.549$ & $22.604 \pm 0.539^{*}$ & $22.665 \pm 0.491^{*}$ \\
\hline
\end{tabular}

The values are means \pm SE. for eight rats per group. ${ }^{*} p<0.05$ vs. diabetic control group. ${ }^{* *} p<0.01$ vs. diabetic control group.

Table 3. Antioxidative effect of RS in the liver and kidney tissues of the tested rats 
activities in NC group compared to DC group $(p<0.01)$, but the level of MDA was significantly increased in diabetic control rats. The increase of MDA level was inhibited significantly by RS treatment in the diabetic rats, and the MDA level was decreased in RS HD group $(p<0.05)$, but the decrease of the level of MDA was not significant in the RS LD group as compared to DC group $(p>0.05)$. In RS treated groups, there was a partial elevation of antioxidant capacity including CAT, SOD and GSH-px in the liver and kidney tissues as compared to DC group ( $p<0.05$ or 0.01 ).

It was reported that diabetic subjects are highly sensitive to oxidative stress (Pritchard et al., 1986). In STZ-diabetic animals, STZ generates nitric oxide, which is a powerful free radical oxidant (Kwon et al., 1994) resulting in an increase in blood glucose level. Several studies have documented the relationships between the increase of free radicals and blood glucose, lipid peroxidation as well as low-density lipoprotein in the progress of diabetes (Rabinovitch et al., 1996; Tanaka et al., 2002). Free radicals can diffuse intracellularly and result in mitochondrial enzyme damage and DNA break, impair cellular function and contributes to the pathophysiology of diabetes (Bonnefont-Rousselot et al., 2000). Increased free radical production exerts cytotoxic effects on the membrane phospholipid, resulting in formation of toxic products such as MDA. Several reports have shown the alterations in the antioxidant enzymes during diabetic condition (Preet et al., 2005). The antioxidative defense system like SOD and CAT showed lower activities in liver and kidney during diabetes. The decreased activities of SOD and CAT may be a response to increased production of $\mathrm{H}_{2} \mathrm{O}_{2}$ and $\mathrm{O}_{2}-$ by the auto oxidation of excess glucose and non-enzymatic glycation of proteins (Argano et al 1997). Pigeolet et al (1990) have reported the partial inactivation of these enzyme activities by hydroxyl radicals and hydrogen peroxide. The decreased activity of SOD and CAT could also be due to their decreased protein expression levels in the diabetic condition as reported recently in liver (Sindhu et al 2004). GSH is often regarded as antioxidant agents, since they protect protein - $\mathrm{SH}$ groups against oxidation and can scavenge oxygen radicals and some other reactive species (Robertson, 2004). It reduces different oxidants after increasing of its hydrogen atom. In these reactions, two GSH molecules transform into one molecule of oxidized glutathione (GSSG). This reaction catalyzes the enzyme GSH-px in cells (Reiter, 1995). In our research, the level of SOD, GSHpx and CAT was increased and the concentration of MDA was decreased after RS treatment, which suggests that RS has effective antioxidative properties and could scavenge well excess free radicals, which may prevent the oxidative damage of the tissues and can increase a protective effect on improving diabetic complications.

\subsection{Single cell gel electrophoresis experiments}

SCGE does not require cell division, and under alkaline conditions, enables the assessment of DNA double-and single-strand breaks and alkali-labile sites (Singh et al., 1988; Belpaeme, et al., 1996). It is a rapid, simple, visual and sensitive technique for measuring DNA breakage in individual mammalian cells.Single cell gel electrophoresis (SCGE) experiment was made. The blood samples were collected from five rats, then lymphocytes were separated from whole blood using a Ficoll Paque lymphocytes separation medium, then 
suspended in PBS (Collins and Dusinska, 2002). Cells were incubated in RPMI 1640 (10\% fetal bovine serum) and exposed to $\mathrm{dH}_{2} \mathrm{O}$ control (same volume), RS (100, $200 \mu \mathrm{g} / \mathrm{ml}$ final concentration) or $\mathrm{H}_{2} \mathrm{O}_{2}(5 \mu \mathrm{mol} / \mathrm{L})$, cultured at $37^{\circ} \mathrm{C}$ in a $5 \% \mathrm{CO}_{2}, 95 \%$ air incubator for $1 \mathrm{~h}$, then cells were centrifuged at $4^{\circ} \mathrm{C}$, suspended in a small volume of PBS. Cells were mixed with $0.5 \%$ low melting temperature agarose at $37^{\circ} \mathrm{C}$, and then placed on a precleaned microscope slides which were already covered with thin layer of $0.5 \%$ normal melting agarose. The slides were immersed in a lysing solution for $1 \mathrm{~h}$ to lyse the cells. Electrophoresis was conducted at $25 \mathrm{~V}$ for $20 \mathrm{~min}$, and then the slides were washed gently to remove alkali and detergents with Tris-buffer, rinsed with $\mathrm{dH}_{2} \mathrm{O}$, and stained with ethidium bromide. Four different cultures were analyses under a fluorescence microscope, the tail lengths of 300 cells per culture evaluated and categorized. Four different cultured lymphocytes were assayed by SCGE. The results were shown in Figure 4 and Table 4 . The percentage of DNA in the tail was calculated to express the amount of DNA damage by [ 2.5 $\times$ cells $0+12.5 \times$ cells $1+30 \times$ cells $2+60 \times$ cells $3+90 \times$ cells 4$) / \sum$ cells] (Collins and Dusinska, 2002). The result showed that RS-treated lymphocytes (low and high doses) were not significantly affected, whose DNA images were similar with $\mathrm{dH}_{2} \mathrm{O}$-treated cultures, whereas the $\mathrm{H}_{2} \mathrm{O}_{2}$-treated cells were heavily damaged. In our study, the results showed that RS had not toxic effect to the cultured lymphocytes' DNA, which were similar with $\mathrm{dH}_{2} \mathrm{O}$-treated.

\begin{tabular}{cccccc}
\hline Scores & Cell 0 & Cell 1 & Cell 2 & Cell 3 & Cell 4 \\
\hline $\begin{array}{c}\text { Percentage } \\
\text { DNA in } \\
\text { the tail }\end{array}$ & $<5$ & $5-20$ & $20-40$ & $40-80$ & $>80$ \\
Average & 2.5 & 12.5 & 30 & 60 & 90 \\
& & & & & \\
Images & & & & & \\
\hline
\end{tabular}

Visual classification of DNA damage, accoding to the relative proportion of DNA in the tail (cells 0-4), obtained by single-cell gel electrophoresis. Cell 0 represents undamaged cells, and cell 4 represents the most heavily damaged cells.

Figure 4. Single Cell Gel Electrophoresis Images of Different Damaged Lymphocytes

\begin{tabular}{lcccccc}
\hline \multicolumn{1}{c}{ Scores } & Cells 0 & Cells 1 & Cells 2 & Cells 3 & Cells 4 & $\begin{array}{c}\text { percentage DNA in } \\
\text { the tail }\end{array}$ \\
\hline $\mathrm{dH}_{2} \mathrm{O}$ & 281 & 19 & 0 & 0 & 0 & 3.13 \\
$\mathrm{RS}(100 \mu \mathrm{g} / \mathrm{ml})$ & 275 & 25 & 0 & 0 & 0 & 3.33 \\
$\mathrm{RS}(200 \mu \mathrm{g} / \mathrm{ml})$ & 271 & 29 & 0 & 0 & 0 & 3.47 \\
$\mathrm{H}_{2} \mathbf{O}_{2}(5 \mu \mathrm{mol} / \mathrm{L})$ & 0 & 8 & 157 & 125 & 10 & 44.03 \\
\hline
\end{tabular}

Cells 0 represents the number of undamaged cells, and Cells 4 represents the most heavily damaged cells.

Table 4. Percentage DNA in the tail of different cultures in SCGE assay 


\section{Antidiabetic and antioxidant effects of oleanolic acid in diabetic rats}

Our study evaluates the antidiabetic and antioxidant effects of oleanolic acid (OA) from Ligustrum lucidum Ait in alloxan-induced diabetic rats. OA in the alloxan-induced diabetic rats showed significant hypoglycemic activity. The levels of serum TC, TG and low-density lipoprotein cholesterol (LDL-c) of OA-treated diabetic rats were lower, and the high-density lipoprotein cholesterol (HDL-c) level was higher than control diabetic rats. Furthermore, OA treatment decreased MDA level, while increased SOD and GSH-Px activities of the liver and kidney in diabetic rats. These results indicate that $\mathrm{OA}$ has the hypoglycemic, hypolipidemic and antioxidant efficacy for the diabetic rats and protects the liver function avoiding alloxan induced damage. The antioxidant ability of OA might be the main mechanism of hypoglycemic and hypolipidemic effects.

\subsection{Sample preparation and characterization}

The extraction of Ligustrum lucidum Ait was based on the multi-crystal method (Gao et al., 2007), and the white powder was obtained. The powder was detected by thin-layer chromatography analysis. The mass spectra and tandem mass spectra were obtained. The authenticity of the purified sample was confirmed. The OA sample was confirmed by electrospray mass spectrometry (Fig.5A, 5B), oleanolic acid is a pentacyclic triterpene $\left(\mathrm{C}_{30} \mathrm{H}_{48} \mathrm{O}_{3}\right)$ and has a molecular weight of 456.71 . The mass spectrum of the purified $\mathrm{OA}$ has indicated the presence of a major fragment at $\mathrm{m} / \mathrm{z} 455.6$ corresponding to the deprotonated molecule $[\mathrm{M}-\mathrm{H}]-$ of OA. The low level of contaminants, observed in this spectrum (for instance at $\mathrm{m} / \mathrm{z} 393$ and at $\mathrm{m} / \mathrm{z} 403$ ) indicated that the sample purification procedure was efficient. To further confirm its structure, tandem mass spectrometry experiment (MS/MS) was performed on the molecular ion fragment at m/z 455.6 (Figure. 1B). Fragmentation of this molecular ion has led to the loss of neutral $\mathrm{CO}_{2}$ molecule detected at $\mathrm{m} / \mathrm{z}$ 407.3. Other abundant fragment ions observed at $\mathrm{m} / \mathrm{z} 391.4, \mathrm{~m} / \mathrm{z} 389.4, \mathrm{~m} / \mathrm{z} 375.4$ and $\mathrm{m} / \mathrm{z} 373.3$, corresponded to demethylation and/or dehydration products of OA. The mass spectrometric analysis results were in agreement with the molecular characteristics of OA.

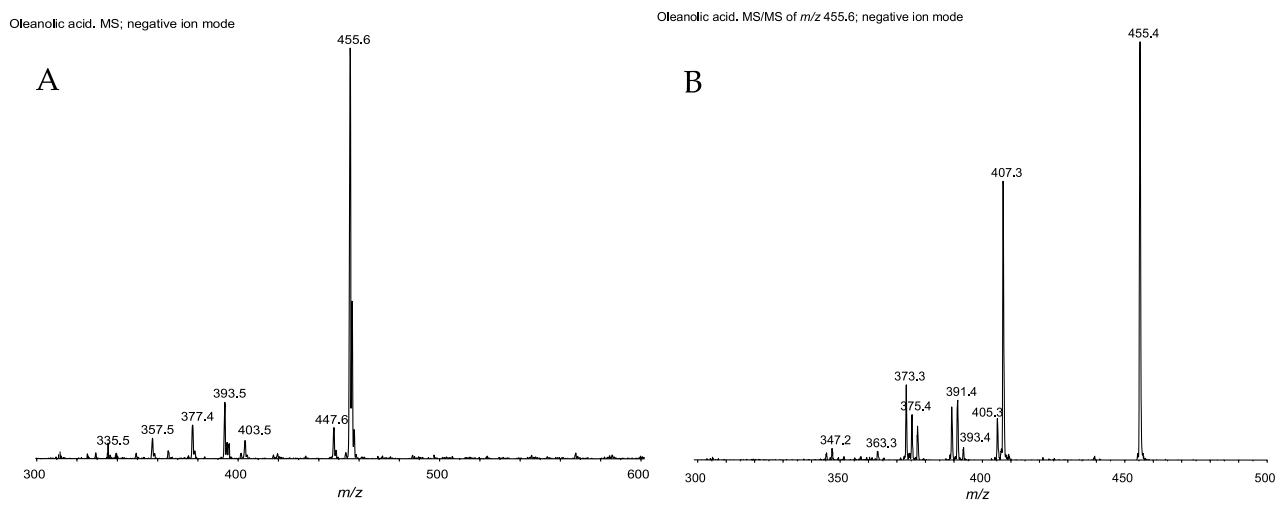

Figure 5. (A) Representative LC/MS chromatogram of OA. (B) Representative LC/MS/MS chromatogram of $\mathrm{OA}$ 


\subsection{Preparation of alloxan-induced diabetic rats}

Wistar rats weighing 180-200 g were purchased and house as previous condition. Eight rats were randomly picked up as normal control (NC), and the rest were fed on high-fat diet. After exposure to the high-fat diet for 3 weeks, the rats were fasted overnight with free access to water, and injected intraperitoneally with alloxan that was dissolved in sterile normal saline solution, and used dosage of alloxan was $200 \mathrm{mg} / \mathrm{kg}$ bw. After injection $72 \mathrm{~h}$, the fasting blood glucose level of the rats was determined according to glucose oxidase method (Trinder, 1969) using a Glucose Analyzer. The blood glucose level above $15 \mathrm{mM}$ was defined as DM rats. Thirty-two rats (8 normal rats, 24 alloxan-induced diabetic rats) were chosen and divided into four groups: normal control group (NC), diabetic control group (DC), diabetes + low-dose OA group (DM + OA LD) and diabetes + high-dose OA (DM + OA HD).

\subsection{Determination hypolipidemic effect of OA}

The rats of $\mathrm{DC}, \mathrm{DM}+\mathrm{OA} \mathrm{LD}$ and $\mathrm{DM}+\mathrm{OA}$ HD groups were fasted overnight with free access to water, blood glucose level of each animal was determined as zero-time blood glucose. The animals of DC group were received $0.5 \%$ carboxymethylcellulose (CMC) solution by gavage. The rats were orally administered OA $60 \mathrm{mg} / \mathrm{kg}$ bw (for the DM + OA LD group) and $100 \mathrm{mg} / \mathrm{kg}$ bw (for the DM + OA HD group), OA was dissolved in $0.5 \% \mathrm{CMC}$ solution. Blood samples of all the rats were taken at 0.5, 1, 2, 4 and 6 hour intervals following the administration and blood plasma glucose levels at various time points were measured. Whereafter, in the DM + OA LD and HD groups, the rats were given OA $(60 \mathrm{mg} / \mathrm{kg} \mathrm{bw}, 100 \mathrm{mg} / \mathrm{kg} \mathrm{bw})$ daily by gavage for 40 days, respectively. In contrast, the control rats (NC\& DM groups) were given the same volume of $0.5 \%$ solution CMC only for 40 days. On day $0,10,20,30$ and 40, blood samples were collected from a tail vein, following overnight fasting, and measured.

The supplement of OA improved the acute blood glucose levels in the rats (Figure 6). There was no significant difference at $0 \mathrm{~h}$ between the DC and OA-treated groups. But in the DM + OA LD and HD groups, hypoglycemic effect of OA became significant $1 \mathrm{~h}$ following oral administration, and reached the peak $2 \mathrm{~h}(p<0.01)$, was still significant $6 \mathrm{~h}$ after oral administration. There was not marked difference for blood glucose levels in diabetic control rats $(p>0.05)$. The blood glucose level of DM + OA HD was lower than that of DM + OA LD, but there was no significant difference $(p>0.05)$.

In the long term test, changes of plasma glucose level as a result of OA treatment are shown in Figure 7. Fasting blood glucose levels were measured on day 0, 10, 20, 30 and day 40. Before treatment of diabetic rats, there was no significant difference for the blood glucose levels among diabetic rats $(p>0.05)$. They were consistently staying at similar levels within the time course of 0 to 40 days in NC group and DC group. However, in DM +OA treated groups significantly lower blood glucose levels were observed as compared to DC group at the same time points, from day 10 to day $40(p<0.01)$. The decreasing rates of the blood glucose levels at day 40 were $32.4 \%$ (in DM + OA LD group) and $46.4 \%$ (in DM + OA HD 
group), respectively. The difference of dose-effect of OA was significant according to the results of blood glucose levels of OA-treated groups $(p<0.05)$.

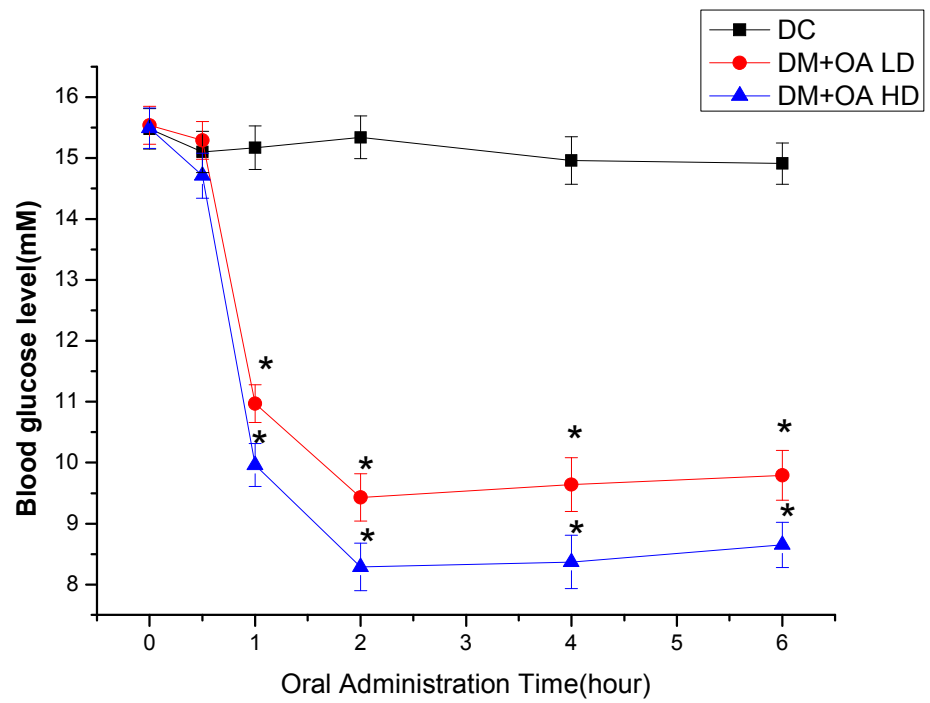

Results of acute blood glucose test for DM+OA LD group, DM+OA HD group and diabetic control group (DC).The values represented the means \pm S.E. for eight rats per group. ${ }^{*} p<0.01$ vs. diabetic control group (DC).

Figure 6. Acute effect of $\mathrm{OA}$ on blood glucose level in diabetic rats

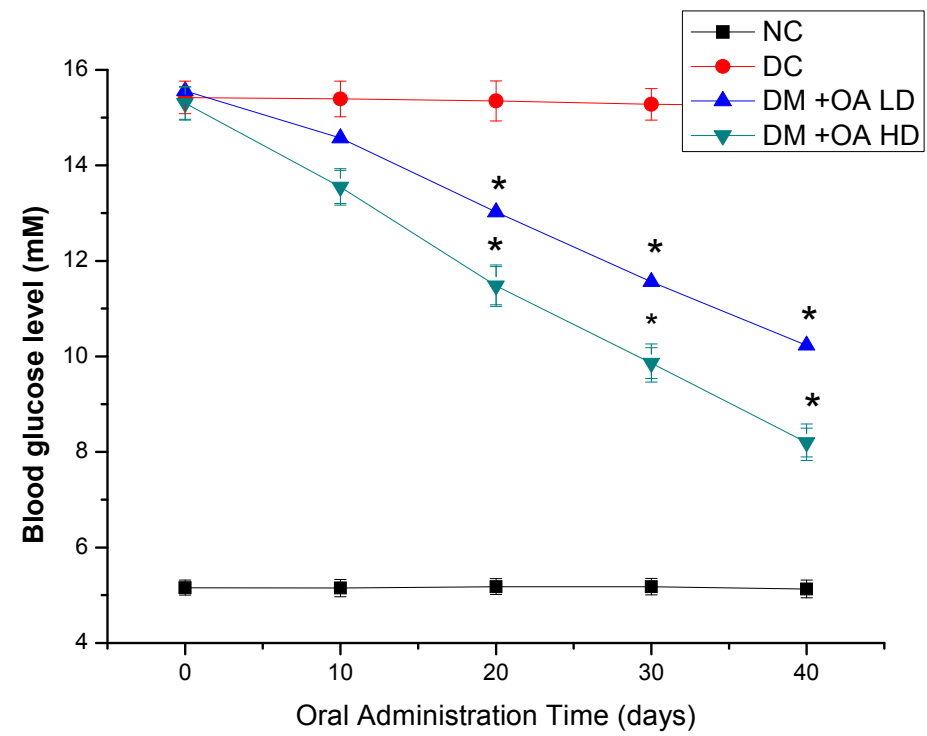

The values represented means \pm S.E. for eight rats per group. ${ }^{*} p<0.01$ vs. diabetic control group (DC).

Figure 7. Long term effect of $\mathrm{OA}$ on blood glucose level in diabetic rats 


\subsection{Determination of blood lipid parameters}

On the day 41, the rats were fasted overnight, and blood samples were collected from eyepit of all rats under ether anaesthesia. The blood samples were used for the measurement of TG, TC, HDL-c and LDL-c levels, according to commercial advice by the Automatic Biochemical Analyzer (Scientific and Technical Center of Beijing Hospital Clinic Medicine, China). Afterthat, the animals were sacrificed under ether anaesthesia. The liver and kidney were immediately removed, weighed and washed using chilled saline solution. Kidney and liver were homogenized in 4 volumes of Tris- $\mathrm{HCl}$ buffer $(\mathrm{pH}$ 7.4). The homogenate was centrifuged at $4000 \times g$ for $20 \mathrm{~min}$ at $4^{\circ} \mathrm{C}$ and the protein concentration was determined using bovine serum albumin as the standard (Bradford et al., 1976). The levels of SOD, MDA and GSH-px were measured by commercial suggestion of the kits.

The long term effect of OA treatment on blood lipid levels of tested rat groups is given in Table 5. The results showed that the levels of TG, TC and LDL-c in DM control rats were significantly higher $(p<0.05$ or 0.01$)$, while their level of HDL-c was significantly lower $(p<$ $0.01)$ than those of NC group. When diabetic rats were treated with $\mathrm{OA}(100 \mathrm{mg} / \mathrm{kg})$ for 40 days, the levels of serum TG, TC, LDL-c were significantly decreased ( $p<0.05$ with LD group, and $p<0.05$ or 0.01 with HD group), but their HDL-c level significantly increased ( $p$ $<0.05$ with LD group and $p<0.01$ with HD group) as compared to DM control group. The lipid metabolic parameters were also affected in OA-treated $(60 \mathrm{mg} / \mathrm{kg})$ rats, but which were less effective than that of OA-treated $(100 \mathrm{mg} / \mathrm{kg})$ rats.

\begin{tabular}{lcccc}
\hline \multicolumn{1}{c}{ Groups } & TG $(\mathrm{mmol} / \mathrm{L})$ & TC $(\mathrm{mmol} / \mathrm{L})$ & LDL-c $(\mathrm{mmol} / \mathrm{L})$ & HDL-c $(\mathrm{mmol} / \mathrm{L})$ \\
\hline NC & $0.946 \pm 0.039^{* *}$ & $1.973 \pm 0.049^{* *}$ & $0.983 \pm 0.033^{*}$ & $0.971 \pm 0.028^{* *}$ \\
DC & $1.396 \pm 0.038$ & $2.460 \pm 0.033$ & $1.145 \pm 0.026$ & $0.825 \pm 0.0278$ \\
DM+OA LD & $1.078 \pm 0.048^{* *}$ & $2.279 \pm 0.031^{*}$ & $1.036 \pm 0.032$ & $0.895 \pm 0.025$ \\
DM+OA HD & $1.014 \pm 0.039^{* *}$ & $1.211 \pm 0.031^{* *}$ & $0.991 \pm 0.034^{*}$ & $0.951 \pm 0.024^{*}$ \\
\hline
\end{tabular}

The values are means \pm S.E. for eight rats per group. ${ }^{*} p<0.05$ vs. diabetic control group (DC). ${ }^{* *} p<0.01$ vs. DC.

Table 5. Effect of OA on serum lipids

Before OA treatment of alloxan-induced diabetic and hyperlipidemic rats, the significant rise in blood glucose was accompanied with increases in TC, TG and LDL-c. After OA treatment, the levels of blood glucose, TC, TG and LDL-c were significantly decreased, and the level of HDL-c in OA-treated rats was higher than those of diabetic rats. These findings indicate that $\mathrm{OA}$ might be beneficial to diabetic patients with atherosclerosis, since elevated HDL-c level is associated with the reduced risk of the development of atherosclerosis in diabetes mellitus (Taskinen et al., 2002). Our results suggested that OA not only possess significant hypoglycemic ability but also have remarkable hypolipidemic effect in alloxaninduced diabetic rats with hyperlipidemia. 


\subsection{Analysis of antioxidative enzyme activities}

The effect of OA on MDA, SOD and GSH-px in the rats is given in Table 6. The results showed that the level of MDA was significantly increased in diabetic control rats, while the activities of SOD and GSH-px were decreased comparing with NC group. The MDA level was decreased in DM +OA HD group $(p<0.05)$, while the decrease of the level of MDA was not significant in the DM+OA LD group as compared to DC group $(p>0.05)$. In OA treated groups, there was a partial elevation of total antioxidant capacity including SOD and GSHpx in the liver and kidney as compared to DC group ( $p<0.05$ or 0.01$)$. The increase of SOD and GSH-px activities of kidney tissue between the DM+OA HD and DM+OA LD groups was shown in the dosage dependent manner $(p<0.05)$.

\begin{tabular}{lcccc}
\hline \multicolumn{1}{c}{ Group } & Tissue & MDA(nmol/mg.pro) & SOD(U/mg.pro) & GSH-px(U/mg.pro) \\
\hline \multirow{2}{*}{ NC } & Liver & $8.22 \pm 0.32^{* *}$ & $45.80 \pm 1.14^{* *}$ & $24.29 \pm 1.00^{* *}$ \\
& kidney & $9.70 \pm 0.27^{* *}$ & $50.35 \pm 1.02^{* *}$ & $32.25 \pm 0.93^{* *}$ \\
DC & liver & $11.18 \pm 0.46$ & $40.16 \pm 0.73$ & $16.55 \pm 0.73$ \\
& kidney & $12.32 \pm 0.35$ & $45.06 \pm 0.54$ & $24.49 \pm 0.73$ \\
DM+OA LD & liver & $9.82 \pm 0.35$ & $42.95 \pm 0.99$ & $19.84 \pm 0.73$ \\
& kidney & $11.69 \pm 0.24$ & $47.43 \pm 0.86$ & $27.30 \pm 0.76$ \\
DM+OA HD & liver & $9.19 \pm 0.42^{*}$ & $44.13 \pm 0.67^{*}$ & $21.35 \pm 1.04^{* *}$ \\
& kidney & $10.6 \pm 0.27^{* *}$ & $48.52 \pm 0.70^{*}$ & $30.68 \pm 0.77^{* *}$ \\
\hline
\end{tabular}

The values are means \pm S.E. for eight rats per group. ${ }^{*} p<0.05$ vs. diabetic control group. ${ }^{* *} p<0.01$ vs. diabetic control group.

Table 6. Effect of OA on tissue MDA, SOD and GSH-Px activities

Alloxan establish a redox cycle with the formation of superoxide radicals. These radicals undergo dismutation to hydrogen peroxide. Thereafter highly reactive hydroxyl radicals are formed. The action of reactive oxygen species with a simultaneous massive increase in cytosolic calcium concentration causes rapid destruction of B cells. Oxygen free radicals exert their cytotoxic effects on membrane phospholipids resulting in the formation of MDA. As the secondary product of lipid peroxidation, MDA would reflect the degree of oxidation in the body. It is a three-carbon dialdehyde, and consists of lipid hydroperoxides. SOD is a scavenger of free radicals, which has important effects on the control of oxidation reactions in the body. The concentration of SOD in diabetes was significantly lower than that of normal (Wohaieb and Godin . 1987).The cause was probably decreased activity of SOD because higher blood glucose could combine with SOD (Fuliang et al., 2005). The level of SOD was increased and the concentration of MDA was decreased after OA treatment. This suggests that OA has effective anti-oxidative properties and could scavenge well excess free radicals and reduce the production of MDA. In our study, the results showed that the GSH-px activity was significantly increased in OA-treated diabetes group compared with diabetes control group. Our research suggests that OA possesses antidiabetic potential in alloxan-induced diabetic rats. Oxidative stress was involved in the early diabetic dysfunction that led to reduced activities of antioxidant enzymes. OA treatment recovered activities of antioxidant enzymes 
and improved liver and kidney function resultantl, which indicated that oleanolic acid was benefit to early diabetic rats due to its antioxidant property partly at least.

\section{Antioxidant therapies of lactic acid bacteria on hypolipidemia}

Pickled cabbage is popular Chinese traditional food. Our study was explored to characterize effects of lactic acid bacteria (LAB) isolated from the pickled cabbages on activities of antioxidant enzymes and hypolipidemia in normal and high fat diet mice. 28 LAB strains were isolated from pickled cabbage, and two strains with high acid tolerance and bile salt resistance were screened. The strains were identified to be L.plantarum (lab1) and L.brevis (lab2) by the API 50CHL identification kit. They were given to normal and hyperlipidemic mice by ig. $28 \mathrm{~d}$ continually. Activities of SOD, GSH-px in liver and kidney tissues of the LAB-treated mice were increased, while change in CAT was insignificant. Differences of SOD levels between the lab2-treated normal diet group and the normal control group was significant $(p<0.05, p<0.01)$. Levels of serum TC, TG and LDL-c were decreased and HDL-c level was higher in the LAB-treated groups. Compared with the high fat food control group, serum TC and TG levels were significant decrease $(p<0.01)$, HDL-c level was significant increase $(p<0.05)$ in lab2-treated and lab1+lab2-treated high fat diet groups. However, the strains can not decrease the blood glucose level of hyperglycemic mice. The result indicates that the strains have the potentials of enhancing activities of antioxidant enzymes and relieving hyperlipidemia-induced oxidative stress.

\subsection{Strains isolation and identification}

LAB strains were isolated using MRS broth from Chinese pickled cabbage that was bought from the Shandongpu market, and identified according to Gram stain positive and catalase test negative. The isolated $\mathrm{LAB}$ strains were stored in $-80^{\circ} \mathrm{C}$.

\subsection{Determination of acid tolerance}

The 28 strains were grown in MRS broth at $37^{\circ} \mathrm{C}$ overnight, and subcultured in $10 \mathrm{~mL}$ of fresh MRS broth adjusted to $\mathrm{pH} 3$ with hydrochloric acid $(3.0 \mathrm{M})$. The initial bacterial concentration was $10^{6} \mathrm{cfu} \mathrm{mL}^{-1}$ and was checked by viable count determination on MRS as described above. Samples were incubated for $4 \mathrm{~h}$ at $37^{\circ} \mathrm{C}$. Cells were serially diluted 10 -fold in phosphate buffer $(0.1 \mathrm{M}, \mathrm{pH}$ 6.2) in order to neutralize the medium acidity. The residual viable count was determined by dilution and plate counting on MRS agar after 24-48 h of incubation. The survival rate was calculated as the percentage of colonies grown on MRS agar compared to the initial bacterial concentration.

\subsection{Bile salt tolerance test}

MRS broth was inoculated with $10^{6} \mathrm{cfu} \mathrm{mL}^{-1}$ from overnight cultures. Growth in control (no bile) and test cultures ( $0.3 \%$ oxgall, Sigma Chemical Co., St. Louis, MO USA) was monitored and incubated for $4 \mathrm{~h}$ at $37^{\circ} \mathrm{C}$. The strains were serially diluted 10 -fold in phosphate buffer $(0.1$ 
$\mathrm{M}, \mathrm{pH}$ 6.2) in order to dilute the medium bile salt. The residual viable count was determined by dilution and plate counting on MRS agar after $24-48 \mathrm{~h}$ of incubation. The survival rate was calculated as the percentage of colonies grown on MRS agar compared to the initial bacterial concentration. In the acid and bile salt tolerance tests, two LAB strains showed high acid tolerance and bile salt resistance. The strains were identified to be L.plantarum (lab1) and L.brevis (lab2) by the API 50CHL identification kit (BioMerieux SA, France) (Gao et al., 2011) , and stored in the Bioengineering laboratory of Yanshan University (Qinhuangdao, China).

\subsection{Experimental design in vivo}

Male ICR mice weighing 18-22 g were purchased from the Experimental Animal Center of China Academy of Military Medical Science (Beijing, China). Fifty-six mice were divided randomly into 7 groups: normal diet control group (NC), high fat diet control group (HFC), lab1 + normal diet group (lab1 + ND), lab1 + high fat diet group (lab1 + HFD), lab2 + normal diet group (lab2 + ND), lab2 + high fat diet group (lab2 + HFD) and mixed bacteria + high fat diet group (MB + HFD). The mice of the HFC, lab1+HFD, lab2+HFD and MB+HFD groups were fed with high fat diet $30 \mathrm{~d}$ continually to construct hyperlipidemic models. On the day 31 , the living lab1 and lab2 suspensions were fed to the mice by ig. $28 \mathrm{~d}$ continually. Experiment groups and feeding treatments are shown in Table 7.

\begin{tabular}{|c|c|c|c|}
\hline Group & $\begin{array}{l}\text { Dosage(MI),Bacteria } \\
\text { Number (cfu mL-1) }\end{array}$ & $\begin{array}{l}\text { Experimental animal } \\
\text { Quantity }\end{array}$ & Feeding method \\
\hline NC & $0.2,2 \times 10^{9}$ & 8 & Normal diet \\
\hline HFC & $0.2,2 \times 10^{9}$ & 8 & High fat diet \\
\hline lab1+DN & $0.2,2 \times 10^{9}$ & 8 & $\begin{array}{l}\text { Lab1 suspension gavage, normal } \\
\text { diet }\end{array}$ \\
\hline lab2+ND & $0.2,2 \times 10^{9}$ & 8 & $\begin{array}{l}\text { Lab1 suspension gavage, high fat } \\
\text { diet }\end{array}$ \\
\hline lab1+HFD & $0.2,2 \times 10^{9}$ & 8 & $\begin{array}{l}\text { Lab2 suspension gavage, normal } \\
\text { diet }\end{array}$ \\
\hline lab2+HFD & $0.2,2 \times 10^{9}$ & 8 & $\begin{array}{l}\text { Lab2 suspension gavage, high fat } \\
\text { diet }\end{array}$ \\
\hline $\mathrm{MB}+\mathrm{HFD}$ & $0.2,2 \times 10^{9}$ & 8 & $\begin{array}{l}\text { Lab1+Lab2 suspension gavage, high } \\
\text { fat diet }\end{array}$ \\
\hline
\end{tabular}

Table 7. Experimental groups and ways of feeding

\subsection{Determination of tissue enzyme activities and blood lipid levels}

On the day 59, the mice were killed under ether anesthesia, and blood samples were collected from eyepit of all the mice. Livers and kidneys of the mice were removed immediately, weighed and washed with cold physiological saline, and the $10 \%$ tissue homogenate was prepared using physiological saline by a cold glass homogenizer. The 
homogenate was centrifuged at $4000 \times \mathrm{g}$ for $15 \mathrm{~min}$ at $4^{\circ} \mathrm{C}$. The protein concentration of the tissues supernatant was determined by the DC Protein Assay Kit (Bio-Rad Labratories; Richmond, CA) based on the lowry colorimetric assay (Lowry et al., 1951) using bovine serum albumin as standard. The levels of CAT, GSH-px, SOD, TC, TG, HDL-c and LDL-c were measured according to the commercial instructions.

SOD plays a very important role in the balance between oxidation and antioxidation. It could eliminate superoxide free radicals and protect body cells against superoxide damage. Figure8 indicates that the decrease in the level of SOD was significant in the HFC group compared with NC group $(p<0.05)$. The levels of SOD were increased in lab1 + ND and lab2 + ND groups compared with NC group, but were not significant. However, the activities of SOD were significant in liver and kidney tissues of lab1 + ND and lab2 + ND groups compared with HFC group $(p<0.01)$. Meanwhile, the activities of SOD in lab1 + HFD, lab2 + HFD and MB + HFD groups in kidney tissues were increased significantly compared with HFC group $(p<0.05)$, and the levels of SOD in liver tissue were enhanced in lab2 + HFD and $\mathrm{MB}+\mathrm{HFD}$ groups than that of HFC group $(p<0.05)$.

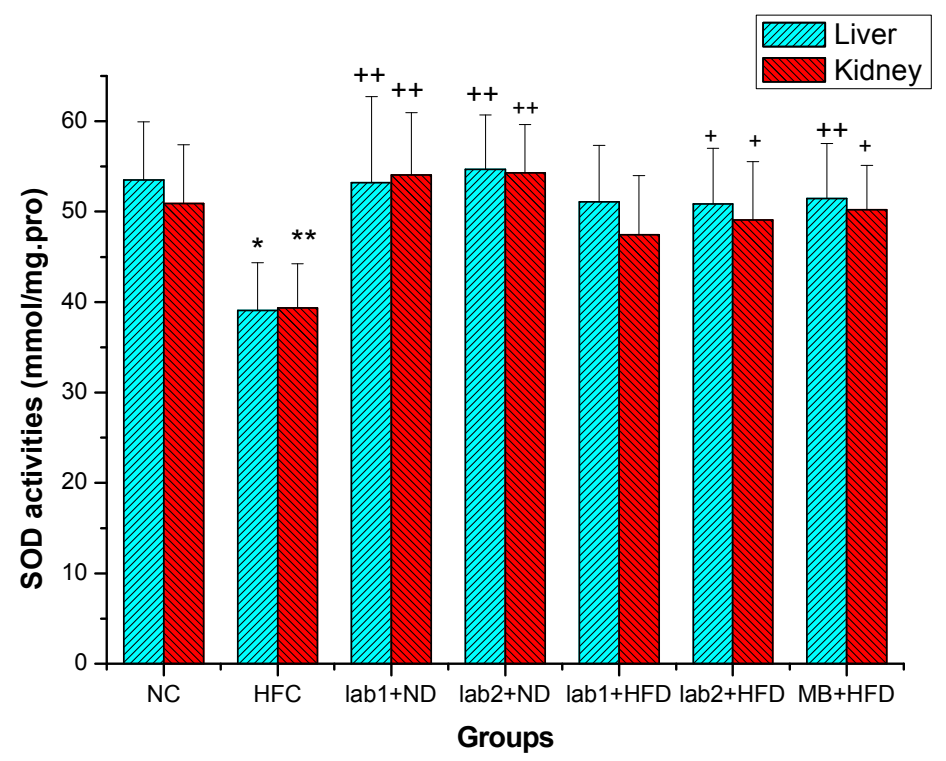

The values are mean \pm SD. ${ }^{*} \mathrm{p}<0.05$ vs normal control group (NC). ${ }^{* *} p<0.01$ vs NC group. ${ }^{+} p<0.05$ vs high fat control group (HFC), ${ }^{+} p<0.01$ vs high fat control group.

Figure 8. Effects of lactic acid bacteria on tissue SOD activities.

GSH-px is a key antioxidant enzyme catalyzing the reduction of peroxides to protect against oxidative tissue damage. Figure 9 shows effects of lactic acid bacteria on tissue GSH-px activities which demonstrate that there was significant difference between NC and HFC groups ( $p$ <.01). GSH-px activities in liver and kidney tissues of lab1 + ND group has not significant difference compared with NC group, but the lab2 + ND group was significantly 
different compared to NC group ( $p<0.05)$. GSH-px levels in the lab1 + HFD, lab2 + HFD and $\mathrm{MB}+\mathrm{HFD}$ groups were different significantly compared with HFC group $(p<0.05,0.01)$.

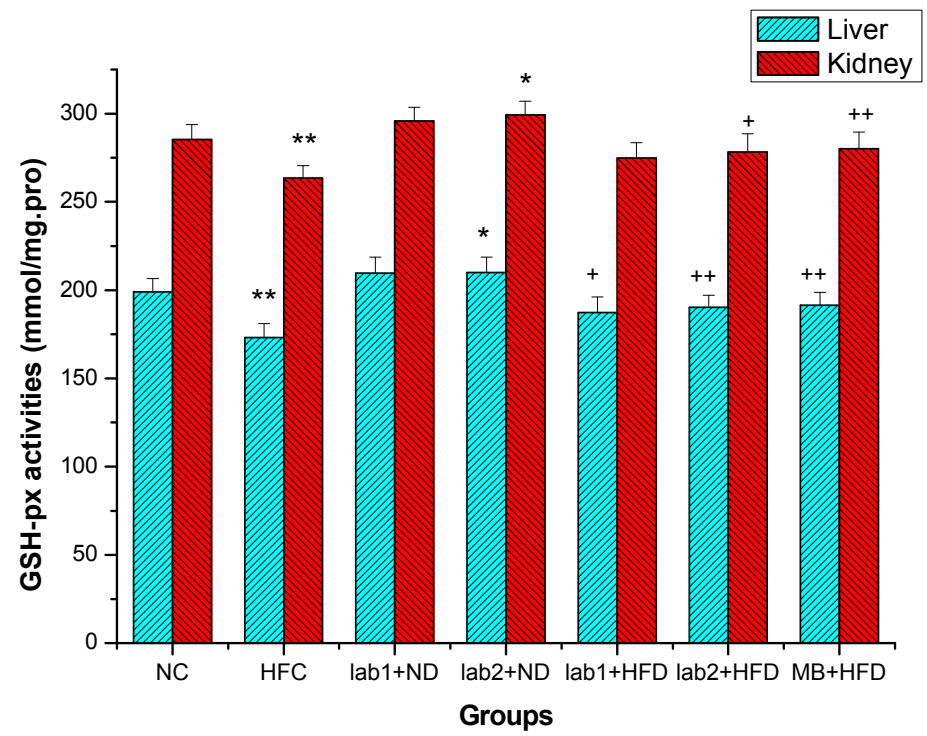

The values are mean $\pm \mathrm{SD} .{ }^{*} p<0.05$ vs normal control group (NC). ${ }^{* *} p<0.01$ vs NC group. $+p<0.05$ vs high fat control group (HFC), ${ }^{+} p<0.01$ vs high fat control group.

Figure 9. Effects of lactic acid bacteria on tissue GSH-px activities

CAT is a main enzy me in the microbody of cells, which can oxygenolysis toxic components (Holmes and Masters 1978). The activities of CAT of liver and kidney tissues for the HFC group were different significantly compared with NC group $(p<0.05)$. However, difference of the levels of CAT was insignificant between all LAB-treated groups and NC group $(p>0.05$, Table 8$)$. The result indicated that the two strains may have no effect on the CAT activities for the LAB-treated mice.

\begin{tabular}{lcc}
\hline \multirow{2}{*}{ Group } & \multicolumn{2}{c}{ CAT (mmol/mg·pro) } \\
\cline { 2 - 3 } NC & Liver & Kidney \\
\hline HFC & $1.08 \pm 0.18$ & $1.07 \pm 0.24$ \\
lab1+DN & $0.79 \pm 0.15^{*}$ & $0.85 \pm 0.15^{*}$ \\
lab2+ND & $0.92 \pm 0.17$ & $1.01 \pm 0.21$ \\
lab1+HFD & $0.94 \pm 0.14$ & $0.99 \pm 0.26$ \\
lab2+HFD & $0.97 \pm 0.14$ & $0.94 \pm 0.14$ \\
MB+HFD & $0.98 \pm 0.12$ & $0.99 \pm 0.21$ \\
\hline
\end{tabular}

The value are mean \pm SD. ${ }^{*} p<0.05$ vs normal control group.

Table 8. Effect of lactic acid bacteria on tissue CAT activities of the tested mice 
The results of TC and TG levels of the experimental mice are presented in Table 9. The levels of TC and TG in lab1 + ND and lab2 + ND groups were slightly lower, but which were not significant compared with NC group. TC and TG levels of hyperlipidemic mice were higher than NC group, and difference was extremely significant $(p<0.01)$, which indicated that the hyperlipidemic models were established. TC and TG levels in lab1 + HFD, lab2 + HFD and $\mathrm{MB}+\mathrm{HFD}$ groups were significantly lower compared to HFC group $(p<0.01)$, and the $\mathrm{MB}+$ HFD group was the lowest, which may be contributed to the mixture of the two strains. The result showed that the two strains have good effects on cholesterol-degrading activity. LDL$\mathrm{c}$ is a main factor of the danger on atherosclerosis, and HDL-c plays an important role in protecting cardiovascular system. HDL-c levels in the LAB-treated hyperlipidemic groups were all higher than HFC group $(p<0.05$ with lab2 + HFD group and $p<0.01$ with MB + HFD), and levels of LDL-c were lower significantly in lab2 + HFD and MB + HFD groups compared with that of high fat control group $(p<0.05$, Table 9$)$.

\begin{tabular}{lcccc}
\hline \multicolumn{1}{c}{ Group } & TC $(\mathrm{mmol} / \mathrm{L})$ & $\mathrm{TG}(\mathrm{mmol} / \mathrm{L})$ & HDL-c $(\mathrm{mmol} / \mathrm{L})$ & LDL-c(mmol/L) \\
\hline NC & $2.76 \pm 0.11$ & $2.35 \pm 0.25$ & $1.88 \pm 0.18$ & $3.81 \pm 0.18$ \\
HFC & $9.03 \pm 0.05^{* *}$ & $5.21 \pm 0.08^{* *}$ & $4.81 \pm 0.02^{* *}$ & $4.99 \pm 0.18^{*}$ \\
lab1+DN & $2.58 \pm 0.16^{++}$ & $2.27 \pm 0.15^{++}$ & $2.01 \pm 0.16$ & $3.37 \pm 0.16$ \\
lab2+ND & $2.674 \pm 0.15^{++}$ & $2.31 \pm 0.24^{++}$ & $2.16 \pm 0.10$ & $3.45 \pm 0.19$ \\
lab1+HFD & $7.12 \pm 0.14$ & $3.86 \pm 0.10$ & $4.98 \pm 0.14$ & $4.19 \pm 0.26$ \\
lab2+HFD & $6.59 \pm 0.04^{++}$ & $3.25 \pm 0.04^{++}$ & $6.22 \pm 0.14^{+}$ & $3.93 \pm 0.32^{+}$ \\
MB+HFD & $6.06 \pm 0.09^{++}$ & $3.02 \pm 0.01^{++}$ & $7.74 \pm 0.03^{++}$ & $3.71 \pm 0.19^{+}$ \\
\hline
\end{tabular}

The values are mean \pm SD. ${ }^{*} p<0.05$ vs normal control group. ${ }^{* *} p<0.01$ vs normal control group. $+p<0.05$ vs high fat control group (HFC), $++p<0.01$ vs high fat control group.

Table 9. Effect of lactic acid bacteria on blood lipid levels

\subsection{Analysis of Nrf2 expression in liver tissues}

Single hepatocyte suspensions of the mice were prepared in ice-cold $0.1 \mathrm{M}$ PBS with $0.1 \%$ sodium azide. Nrf2 antibodies (Santa Cruze biotechnology Inc., USA) were diluted in $0.1 \mathrm{M}$ PBS with $0.1 \mathrm{NaN}_{3} .10^{6}$ cells were incubated with primary anti-Nrf2 antibodies for $30 \mathrm{~min}$ on ice. After two washes in $0.1 \mathrm{M}$ PBS with $0.1 \%$ sodium azide, $0.5 \mu \mathrm{g}$ of secondary FITCconjugated rabbit anti-mouse antibody were added and incubated on ice for $30 \mathrm{~min}$. Finally, the cells were resuspended in $1 \mathrm{~mL}$ of $0.1 \mathrm{M}$ PBS with $0.1 \%$ sodium azide. The hepatocytes were scanned using a FACSCalibur (Becton-Dickinson, USA), and fluorescence of Nrf2 positive cells was quantified. Nonspecific binding of secondary antibody was excluded by incubating the cells only with the FITC-labelled secondary antibody, and the experiment was repeated three times. The software used was BD CellQuest Pro (Becton Dickinson Biosciences, USA) and the data were expressed as fluorescence intensity formula ( $I=\log (x-$ mode) $\times$ 340) (Gao et al., 2011). Nrf2 serves as master regular of a cellular defense system against oxidative stress. In order to identify the effects of two strains on Nrf2 expresssion in 
vivo, we analysed Nrf2 concentration in the hepatic cells for lab1and lab2-treated mice. Nrf2 levels of the hepatocyte nuclear extract were measured by Flow cytometry technology, and the results showed the two strains significantly increased translocated nuclear expression of Nrf2 (vs. untreated normal control; $P<0.01$ ), in accordance with a decrease in untreated high fat diet mice $(P<0.01$, Figure 10, Table 10). The data also indicated that supplementation of Lab strains promoted further translocation of Nrf2 into the nucleus, and activated expression of Nrf2 in the hepatic nucleus of HFD-induced hyperlipidemic mice, as evidenced by a significant elevation of Nrf2 in the nuclear fractions $(P<0.05)$.

\begin{tabular}{lc}
\hline \multicolumn{1}{c}{ Group } & Nrf2 expression fluorescence intensity \\
\hline NC & $219.86 \pm 3.42$ \\
HFC & $144.67 \pm 6.82$ \\
lab1+ND & $211.88 \pm 3.15^{*}$ \\
lab2+ND & $285.56 \pm 2.49^{*}$ \\
lab1+HFD & $200.27 \pm 4.00^{+}$ \\
lab2+HFD & $275.62 \pm 2.16^{+}$ \\
MB+HFD & $286.25 \pm 2.93^{+}$ \\
\hline
\end{tabular}

*Significantly different from normal control group, $P<0.01$; ${ }^{+}$Significantly different from high fat control group, $P<0.01$.

Table 10. Effect of LAB on expression of Nrf2 protein of liver cells in the mice

Single-colour histograms represent hepatocyte staining with anti-Nrf2 antibodies; x-axis, DTAF flurescence intensity; y-axis, frequency of cells displaying certain fluorescence intensity. A was normal control group; B was lab1 treated normal mice; C was lab2 -treated normal mice; D was lab+lab2-treated normal mice; E was high fat control group; F was lab1 treated high fat mice; $\mathrm{G}$ was Lab2 treated high fat mice; $\mathrm{H}$ was lab1+lab2 treated high fat mice.

Probiotics are commonly used as viable microbial feed supplements that affect the host animal by improving its intestinal microbial "balance" (Holzapfel, et al., 1998). Several studies demonstrated that some lactobacilli possess antioxidative activity, and could decrease the risk of accumulation of reactive oxygen species during the ingestion of food (Ito, et al., 2003; Kuda et al., 2010). However, probiotic bacteria must be resistant to the acidity of the stomach, lysozyme, bile, pancreatic enzymes. High acidity in the stomach and high concentration of bile components in the proximal intestine are the first host factors, which affect strain selection and adhesion. In our study, two high acid tolerance and bile salt resistance strains were screened, which were L.plantarum and L.brevis, respectively. Activities of antioxidant enzymes and the function of reducing cholesterol and blood glucose of the two LAB strains were studied. The experimental mice were divided into normal diet and high fat diet groups. The concentration of blood lipids in the normal diet mice was under normal range. When the mice have been fed high fat food for $30 \mathrm{~d}$, the levels of TC, TG and glucose in the blood were higher than those of normal diet mice, 

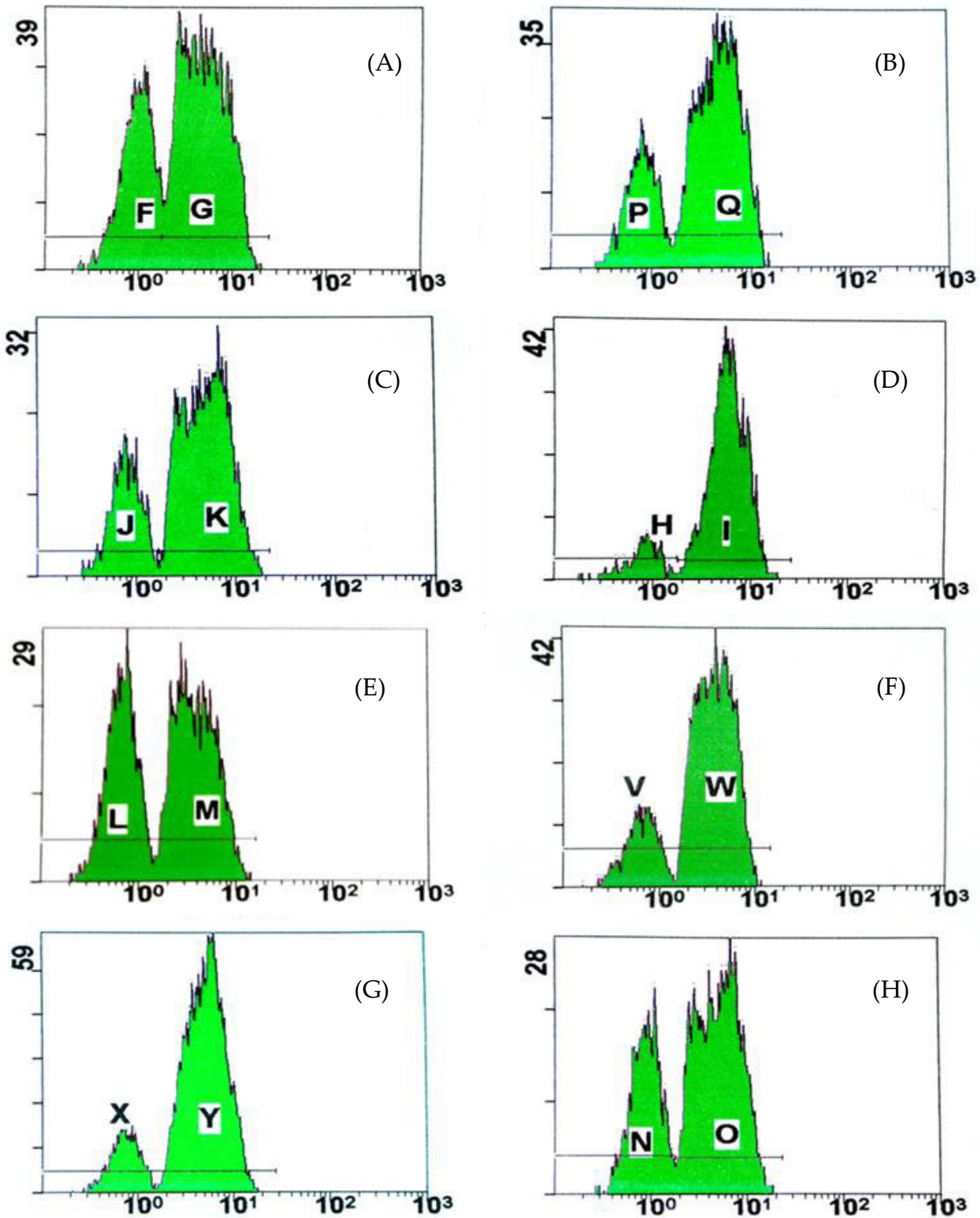

Single-colour histograms represent hepatocyte staining with anti-Nrf2 antibodies; $x$-axis, DTAF flurescence intensity; $\mathrm{y}$-axis, frequency of cells displaying certain fluorescence intensity. A was normal control group; B was lab1 treated normal mice; $\mathrm{C}$ was lab2 -treated normal mice; D was lab+lab2-treated normal mice; $\mathrm{E}$ was high fat control group; F was lab1 treated high fat mice; $\mathrm{G}$ was Lab2 treated high fat mice; $\mathrm{H}$ was lab1+lab2 treated high fat mice.

Figure 10. Flow cytometric analysis of Nrf2 expression in the liver tissues of lactic acid bacteria treated mice and control mice. 
respectively. Levels of serum TC, TG and LDL-c were slightly decreased and HDL-c level was a little higher by the LAB suspension treating on the normal mice. However, compared to the HFC group, levels of TC and TG were decreased extremely in lab2 + HFD and MB + HFD groups. The finding indicates that the two strains might decrease the risks for cardiovascular and arteriosclerosis diseases in various degrees, and it also could fall significantly the cholesterol level in hyperlipidemic mice. Akalin et al. (1997) found that consumption of acidophilus yogurt significantly lowered the values for plasma TC, LDL-c in the mice. After the male SD rats were fed high-fat diet with Lactobacillus ferment, there were significantly decrease on the levels of body weight, LDL-c and TC compared with the highfat diet control rats (Choi et al., 2006). Researchers showed that LAB could decrease the level of cholesterol but the mechanism has not been demonstrated clearly yet. Some predicted that LAB, bile salt and cholesterol were coprecipitated, and then expelled with feces, or the cholesterol was absorpted by lactic acid bacteria (Jeun, et al., 2010). Otherwise, Smet et al. (1994) suggested that the reason of LAB reducing cholesterol might be due to the activity of bile salt hydrolysis produced by the LAB. Further research is indispensable to clarify the exact mechanism.

Several studies have documented the relationships between increase of free radicals and blood glucose, lipid peroxidation as well as low-density lipoprotein (Tanaka et al., 2002). High fat diet could be used to induce significant oxygen-centered free radicals and ROS generation in the mice. The liver plays a central role in the maintenance of systemic lipid homeostasis and it is especially susceptible to reactive oxygen species (ROSs) damage (Hamelet et al., 2007). Free radicals can diffuse intracellularly and result in mitochondrial enzyme damage and DNA breaks, impair cellular function (Bonnefont-Rousselot et al., 2000). SOD is a scavenger of free radicals, which has important effects on control of oxidation reactions in the body. Some LAB may enhance SOD and GSH-px activities and prevent oxidative damage (Tsai, et al., 2009). GSH is often regarded as an antioxidant agent, since it protects protein - $\mathrm{SH}$ groups against oxidation and can scavenge oxygen radicals and some other reactive species. It reduces different oxidants after increasing its hydrogen atom. This reaction is catalysed by enzyme GSH-px in cells (Reiter, 1995). In the research, the concentration of SOD and GSH-px in the high fat diet mice was significantly lower than those of the normal rats. Meanwhile, the activities of SOD and GSH-px were increased in various degrees in Lab1 + ND and lab2 + ND groups compared with the normal control mice after the LAB administering. The levels of SOD and GSH-px in the lab1 + HFD, lab2 + HFD and MB + HFD groups were all increased compared with HFC group, but not achieve the level of the NC group. In this study, the levels of antioxidant enzymes and the function of reducing blood lipid in MB + HFD groups were higher than the other two hyperlipidemic groups. SOD is the most important survival protein and ubiquitously induced antioxidant by various stimulants, so we hypothesized that the strains might play a more crucial role in a severe stressful condition. At the same time, supplementation of Lab also promoted expression of Nrf2 in the liver tissues of the mice. Nrf2 serves as master regular of a cellular defense system against oxidative stress (Motohashi et al., 2004; Nguyen et al., 2004). Under physiological conditions, Nrf2 is sequestered in the cytoplasm by Keap1, which facilitates its 
ubiquitination and proteasomic degradation (Kang, et al., 2004)Upon exposure to oxidative stress, the sequestration complex breaks down and the dissociated Nrf2 translocates into the nucleus, where it binds to cis-acting antioxidant response elements (AREs) and promotes the transcription of a large number of cytoprotective genes (Kensler et al., 2007; Vries et al., 2008). Nrf2-ARE signaling is also known to be mainly responsible for the upregulation of SOD and GSH-px gene expression and hence constitutes a crucial cellular response to environmental stresses (Surh et al., 2009). L.plantarum is further capable of activation of Nrf2 and preventing HFD-induced inhibition of antioxidant enzymes. Our Flow cytometry data clearly show that high fat diet-induced oxidative stress is associated with activation of $\mathrm{Nrf2}$, as evidenced by a significant elevation of $\mathrm{Nrf} 2$ in the nuclear fractions $(\mathrm{P}<0.05)$. Supplementation of L.plantarum markedly promoted further translocation of Nrf2 into the nucleus. Thus, L.plantarum could inhibit HFD-induced oxidative stress through the Nrf2Keap1 signaling pathway. As expected, L. plantarum isolated from fermented cabbage upregulates antioxidative enzymes in high fat diet mice via Nrf2-dependent transcriptional activation of ARE sites. The upregulation of several antioxidative enzymes is associated with the reduced formation of ROS and enhanced survival of liver cells upon the induction of oxidative stress.

\section{Author details}

Dawei Gao

Key Laboratory of Applied Chemistry in Hebei Province, Department of Biological Engineering, Yanshan University, Qinhuangdao, China

\section{Acknowledgement}

This work was financially supported by the research grant from the Chinese Ministry of Education Doctor Degree (No. 20101333120011), a grant from Hebei Province Natural Science Fund (No. C2011203137, 11965152D), and a Chinese Postdoctoral grant (480013).

\section{References}

Akalin AS, Gonc S, Duzel S. Influence of yogurt and acidophilus yogurt on serum cholesterol levels in mice. J. Dairy Sci. 1997, 80: 2721-2725.

Aksoy N, Vural H, Sabuncu T, Aksoy S. Effects of melatonin on oxidative-antioxidative status of tissues in streptozotocin-induced diabetic rats. Cell Biochem Funct. 2003, 21:121-125.

Alexander R. W. Hypertension and the Pathogenesis of Atherosclerosis Oxidative Stress and the Mediation of Arterial Inflammatory Response: A New Perspective.Hypertension 1995, 25:155-161.

Argano M., Brignardello E., Tamagno O.Gatto V., Danni O., Boccuzzi G. Dehydroeppiandrosterone administration prevents the oxidative damage induced by acute hyperglycemia in rats. J Endocrinol 1997,155: 233-240 
Belpaeme K., Delbeke K., Zhu L., Kirsch-Volders M.Cytogenetic studies of PCB77 on brown trout (Salmo trutta fario) using the micronucleus test and the alkaline comet assay. Mutagenesis 1996, 11:485-492

Bradford M.M. A rapid and sensitive method for the quantitation of microgram quantities of protein utilizing the principle of protein-dye binding. Anal Biochem 1976, 72: 248-254

Brown N.S., Bicknell R. Hypoxia and oxidative stress in breast cancer Oxidative stress: its effects on the growth, metastatic potential and response to therapy of breast cancer. Breast Cancer Res 2001, 3:323-327

Bonnefont-Rousselot D, Bastard JP, Jaudon MC, Delattre J. Consequences of the diabetic status on the oxidant/antioxidant balance. Diabetes Metab. 2000, 26:163-176

Choi YM, Bae SH, Kang DH, Suh HJ. Hypolipidemic effect of lactobacillus ferment as a functional food supplement. Phytother Res. 2006, 20:1056-1060

Collins A.R., Dusinska M. Oxidation of cellular DNA measured with the comet assay. Meth Mol Biol 2002, 6:147-159

Fuliang HU, Hepburn HR, Xuan H, Chen M, Daya S, Radloff SE. Effects of propolis on blood glucose, blood lipid and free radicals in rats with diabetes mellitus. Pharmacol Res. 2005, 51:147-152.

Furukawa S., Fujita T., Shimabukuro M., Iwaki M, et al. Increased oxidative stress in obesity and its impact on metabolic syndrome. J Clin Invest. 2004,114:1752-1761

Gao D, Zhu G.Antioxidative and hypolipidemic effects of lactic acid bacteria from pickled Chinese cabbage. Journal of Medicinal Plants Research 2011,5:1439-1446

Gao D., Li Q., Li Y., et al. Antidiabetic potential of oleanolic acid from Ligustrum lucidum Ait. Can J Physiol Pharmacol 2007, 85:1076-83.

Gao D., Li Q, Liu Z. Antidiabetic potential of rhodiola Sachalinensis root extract in Streptozotocin-induced diabetic rats. Methods Find Exp Clin Pharmacol 2009,31: 375381

Girotti MW. Mechanisms of lipid peroxidation. Free Radic Biol Med. 1985, 1:87-95.

Haberer P, Toit MD, Dicks LMT, Ahrens F, Holzapfel WH. Effect of potentially probiotic lactobacilli on faecal enzyme activity in minipigs on a high-fat, high-cholesterol diet-a preliminary in vivo trial. Int. J. Food Microbiol. 2003,87: 287-291.

Hamelet J., Demuth K., Paul J., Hyperhomocysteinemia due to cystathionine beta synthase deficiency induces dysregulation of genes involved in hepatic lipid homeostasis in mice. J Hepatology 2007,46:151-159

Hao ZQ, Hang BQ, Wang Y. Study of Ligustrum lucidum Ait on decreasing blood glucose. Chinese Materia Medica. 1992, 17: 429-431

Holmes R.S. and Masters C.J.Genetic control and ontogeny of microbody enzymes: A review Biochemical genetics 1978,16:171-190

Holzapfel WH, Haberer P, Snel J, Schillinger U, Huis int Veld JHJ.Overview of gut flora and probiotics. Int. J. Food Microbiol. 1998,41:85-101

Ito M, Ohishi K, Yoshida Y, Yokoi W, Sawada H.Antioxidative effects of lactic acid bacteria on the colonic mucosa of Iron-overloaded mice. J. Agric. Food Chem. 2003,51: 44564460 
Jain S,Yadav H, Sinha PR.Antioxidant and cholesterol assimilation activities of selected lactobacilli and lactococci cultures. J. Dairy Res. 2009,76:385-391

Jeun J, Kim S, Cho SY, Jun H, Park HJ, Seo JG, Chung MJ, Lee SJ. Hypocholesterolemic effects of Lactobacillus plantarum KCTC3928 by increased bile acid excretion in C57BL/6 mice. Nutrition. 2010,26: 321-330

Kang M., Kobayashi A., Wakabayashi N., Kim S., Yamamoto M.Scaffolding of Keap1 to the actin cytoskeleton controls the function of Nrf2 as key regulator of cytoprotective phase 2 genes. National Acad Sciences 2004, 17: 2046-2051

Kawase M, Hashimoto H, Hosoda M, Morita H, Hosono A. Effect of administration of fermented milk containing whey protein concentrate to rats and healthy men on serum lipids and blood pressure. J. Dairy Sci. 2000,83: 255-263

Kensler, T.W., Wakabayashi, N., Biswal, S. Cell survival responses to environmental stress via the Keap1-Nrf2-ARE pathway. Annu. Rev. Pharmacol. Toxicol.2007,47:89-116

Kuda T, Kaneko N, Yano T, Mori M. Induction of superoxide anion radical scavenging capacity in Japanese white radish juice and milk by Lactobacillus plantarum isolated from aji-narezushi and kaburazushi Food Chemistry 2010,120:517-522

Kwon N.S., Lee S.H., Choi C.S., Kho T., Lee HS. Nitric oxide generation from streptozotocin. FASEB J 1994, 8:529-33.

Li T, Xu G, Wu L, Sun C. Pharmacological studies on the sedative and hypnotic effect of salidroside from the Chinese medicinal plant Rhodiola sachalinensis. Phytomedicine 2007,14:601-604

Lowry OH, Rosebrough NJ, Farr AL, Randall RJ. Protein measurement with the Folin phenol reagent. J. Biol. Chem. 1951,193: 265-275

Matafome P., Louro T., Rodrigues L. et al., Metformin and atorvastatin combination further protect the liver in type 2 diabetes with hyperlipidaemia. Diabetes Metabolism Res Reviews. 2011,27:54-62.

Ming H.Q., Xia G.C., Zhang R.D. Progress in Rhodiola rosea L. Chin. Traditional Herbal Drugs. 1988, 19: 37-42.

Mook-Jung I., Kim H., Fan W., Tezuka Y., Kadota S., Nishijo H., Jung M.W. Neuroprotective effects of constituents of the oriental crude drugs, Rhodiola sacra, $R$. sachalinensis and Tokaku-joki-to, against beta-amyloid toxicity, oxidative stress and apoptosis.Biol Pharm Bull 2002, 25:1101-1104

Motohashi, H., Yamamoto, M. Nrf2-Keap1 defines a physiologically important stress response mechanism. Trends Mol. Med., 2004,10: 549-557

Nguyen, T., Nioi, P., Pickett, C.B. The Nrf2-antioxidant response element signaling pathway and its activation by oxidative stress. J. Biol. Chem., 2009,284:13291-13295

Pigeolet E., Corbisier P., Houbion A. Glutathione peroxidase, superoxide dismutase and Catalase inactivation by peroxides and oxygen derived free radicals. Mech Aging Dev 1990, 51:283-297

Preet A., Gupta B.L., Yadava P.K., Baquer N.Z. Efficacy of lower doses of vanadium in restoring altered glucose metabolism and antioxidant status in diabetic rat lenses. J Biosci 2005, 30: 221-230. 
Pritchard J.R., Patel S.T., Karpen C.W., et al. Triglyceride- lowering effect of dietary vitamin $\mathrm{E}$ in streptozotocin-induced diabetic rats. Increased lipoprotein lipase activity in livers of diabetic rats fed high dietary vitamin E. Diabetes 1986,35: 278-281.

Rabinovitch A., Suarez-Pinzon W.L., Strynadka K., Lakey J R., Rajotte R V. Human pancreatic islet beta-cell destruction by cytokines involves oxygen free radicals and aldehyde production. J Clin Endocrinol Metab 1996, 81: 3197-3202.

Reiter RJ. Oxidative processes and antioxidative defense mechanisms in the aging brain. FASEB J. 1995, 9:526-533.

Robertson RP. Chronic oxidative stress as a central mechanism for glucose toxicity in pancreatic islet beta cells in diabetes. J Biol Chem. 2004,279: 42351-42354

Sakatani T, Shirayama T, Suzaki Y, Yamamoto T, Mani H, Kawasaki T, Sugihara H, Matsubara H. 2005. The association between cholesterol and mortality in heart failure. Comparison between patients with and without coronary artery disease. Int Heart J. 46: 619-629

Sezik E., Aslan M., Yesilada E., Ito S. Hypoglycaemic activity of Gentiana olivieri and isolation of the active constituent through bioassay-directed fractionation techniques.Life Sci. 2005, 76: 1223-1238

Sharma SB, Nasir A, Prabhu KM, Murthy PS, Dev G. Hypoglycaemic and hypolipidemic effect of ethanolic extract of seeds of Eugenia jambolana in alloxan-induced diabetic rabbits. J Ethnopharmacol. 2003, 85: 201-206

Sindhu R.K., Koo J.R., Roberts C.K. Nosratola D., Vaziri M.D. Dysregulation of hepatic superoxide dismutase, catalase and glutathione peroxidase in diabetes response to insulin and antioxidant therapies. Clin Exp Hypertens 2004, 26: 43-53.

Singh N.P., McCoy M.T., Tice R.R.,Schneider E.L. A simple technique for quantitation of low levels of DNA damage in individual cells. Exp Cell Res 1988,175:184-191

Smet ID, Hoorde L.V, Saeyer ND, Woestyne M.V, Verstraete W.In vitro study of bile salt hydrolase (BSH) activity of $\mathrm{BSH}$ isogenic lactobacillus plantarum 80 strains and estimation of cholesterol lowering through enhanced BSH activity. Microb. Ecol. Health Dis. 1994, 7:315-329

Stancheva, S.L., Mosharrof, A., Effect of the extract of Rhodiola rosea L. on the content of the brain biogenic monamines. Med Physiol 1987, 40: 85-87

Sotiroudis G, Melliou E, Sotiroudis T, Chinou I. Chemical analysis, antioxidant and antimicrobial activity of three greek cucumber (cucumis sativus) cultivars. J food biochemistry 2010,34: 61-78

Surh, Y.J., Kundu, J.K., Li, M.H., Na, H.K., Cha, Y.N. Role of Nrf2-mediated heme oxygenase-1 upregulation in adaptive survival response to nitrosative stress. Arch. Pharm. Res. 2009,32:1163-1176

Tanaka Y., Tran P.O., Harmon J., Robertson R.P. A role for glutathione Peroxidase in protecting pancreatic $\beta$ cells against oxidative stress in a model of glucose toxicity. Proc Natl Acad Sci USA 2002, 99: 12363-12368

Tsai TU, Chu LH, Lee CL, Pan TM. Atherosclerosis-preventing activity of lactic acid bacteria-fermented milk-soymilk supplemented with Momordica charantia. J. Agric. Food Chem. 2009,57: 2065-2071 
Taskinen MR. Diabetic dyslipidemia. Atheroscler Suppl. 2002,3: 47-51

Trinder P. Determination of blood glucose using an oxidase-peroxidase system with a noncarcinogenic chromogen. J Clin Pathol. 1969,22: 158-161

Vries, H.E., Witte, M., Hondius, D., Rozemuller, A.J., Drukarch, B., Hoozemans, J., van Horssen, J. Nrf2-induced antioxidant protection: a promising target to counteract ROSmediated damage in neurodegenerative disease? Free Radic. Biol. Med. 2008,45: 13751383

Wang ZX, Gao BZ, Xu BY, Huang GC. Study on antimutagenic effect of Ligustrum lucidum Ait by drosophila test. Fujian J. Traditional Chinese Medicine 1991,22: 50-51

Wohaieb SA, Godin DV. Alleviations in free radical tissue defense mechanisms in streptozotocin-induced diabetes in rats: Effects of insulin treatment. Diabetes. 1987,36:1014-1018

Xiang M, Gu ZL. Antitumor effect of Ligustrum lucidum Ait extract in vivo. Jiangsu Medical J. Clin. Res. 2002,10: 13-15

Yin YS, Yu CS. Study on chemical components and hepatoprotective properties of Ligustrum lucidum Ait. Chinese Traditional Patent Medicine 1993,15: 18-19 